\title{
High-Definition Differential Ion Mobility Spectrometry with Resolving Power up to $\mathbf{5 0 0}$
}

\author{
Alexandre A. Shvartsburg, Tom A. Seim, William F. Danielson, Randy Norheim, \\ Ronald J. Moore, Gordon A. Anderson, Richard D. Smith \\ Biological Sciences Division, Pacific Northwest National Laboratory, Richland, WA 99352, USA
}

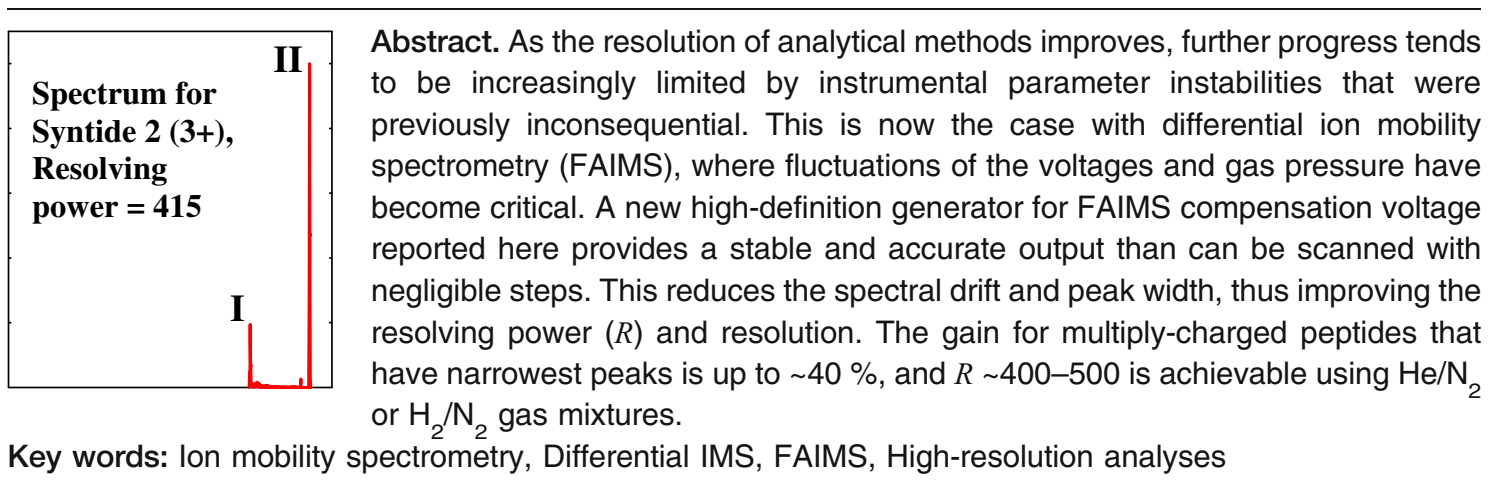

Received: 30 July 2012/Revised: 5 October 2012/Accepted: 8 October 2012/Published online: 20 December 2012

\section{Introduction}

A $\mathrm{n}$ unglamorous yet crucial facet of analytical sciences is the art of precise measurement. Once a novel experimental concept is established, it takes a sustained effort to substantially tighten the precision and accuracy by identifying and minimizing various sources of systematic and random error in the instrumental method and data interpretation. We have embarked on such an endeavor to improve the resolving power $(R)$, precision, and accuracy of field asymmetric waveform ion mobility spectrometry (FAIMS).

Mobilities of ions in gases $(K)$ depend on the electric field intensity $(E)$, and FAIMS captures the increment of $K$ between two $E$ values directly, employing a periodic asymmetric field in a gap between two electrodes that carry a corresponding voltage waveform $[1,2]$. Had the $K(E)$ function been flat, ions would have oscillated across the gap without separation. As the mean $E$ values and, therefore, mobilities for any species at two waveform polarities differ, all ions experience net drift (on top of oscillation) toward either electrode where they are neutralized on contact $[1,2]$. For a particular species, that drift can be offset by a constant weak "compensation field" $\left(E_{\mathrm{C}}\right)$ superposed on the above separating field. That species is equilibrated

Electronic supplementary material The online version of this article (doi:10.1007/s13361-012-0517-5) contains supplementary material, which is available to authorized users.

Correspondence to: Alexandre A. Shvartsburg; e-mail: alexandre.shvartsburg@, pnl.gov in the gap and, pulled by gas flow, can traverse the gap and be registered by a mass spectrometer or another detector. Thus, scanning $E_{\mathrm{C}}$ reveals the spectrum of ions entering the gap. The ideal rectangular waveform profile is a challenge to engineer at the voltages needed for high resolution, and suboptimum but more practical profiles based on harmonic oscillations have been adopted [2-4]. Here, we use the most common bisinusoidal profile.

Initially, FAIMS was implemented in the 1980s in portable instruments for detection of explosives and airborne chemical pollutants $[2,5]$. A decade ago, integration with electrospray ionization mass spectrometry (ESI/MS) launched the ongoing expansion of FAIMS to biological and environmental analyses, including in proteomics and metabolomics [6, 7]. These applications involve extraordinarily complex mixtures, creating a virtually open-ended need for resolution and peak capacity of separations preceding the MS step [8]. Hence, the resolving powers of liquid chromatography and conventional IMS (based on the absolute ion mobilities) are steadily increasing [9, 10].

In FAIMS, $R$ is defined as $E_{\mathrm{C}}$ divided by the peak width at half maximum $(w)$ and, thus, depends on the species [2]. However, the value(s) for a given analyte or set of similar analytes (e.g., tryptic peptides) can be used to compare the separation power with different instruments or regimes. The resolving power of FAIMS remained low $(\sim 10)$ for the two decades since its invention $[11,12]$, but has improved to $>100$ in recent years [12-19]. First, the realization that inhomogeneous electric field in curved analytical gaps necessarily 
constrains resolution by allowing multiple equilibrium conditions has led to the transition from cylindrical (spherical) to planar gaps with homogeneous field, where only one species can be stable [13]. Second, higher amplitude of separating field (termed the dispersion field, $E_{\mathrm{D}}$ ) and utilization of buffer gases lighter than air (such as $\mathrm{He}$ ) that raise $K$ dramatically improve resolution with planar FAIMS devices, as the peak separation generally grows while all peaks narrow [12, 14-16]. (In curved gaps, increasing $E_{\mathrm{D}}$ and/or the He fraction tends to also raise $\mathrm{CV}$ and, thus, improve resolution, but concomitant peak broadening moderates the gain [20]). In particular, use of $\mathrm{He} /$ $\mathrm{N}_{2}$ mixtures with up to $75 \% \mathrm{He}(\mathrm{vol} / \mathrm{vol})$ at $E_{\mathrm{D}}=21 \mathrm{kV} / \mathrm{cm}$ or $50 \% \mathrm{He}$ at $E_{\mathrm{D}}=27 \mathrm{kV} / \mathrm{cm}$ has enabled raising $R$ for the reserpine standard with charge state $(z)$ of $1+$ to $\sim 30$ and for peptides with $z=3$ or 4 to $\sim 200$ using the "normal" filtering time $[14,15]$ of $t=0.2 \mathrm{~s}$ and to $\sim 60$ and $\sim 300$, respectively, at extended [16] $t \sim 0.5-0.8 \mathrm{~s}$. Continued increases of $E_{\mathrm{D}}$ and/or He content would have augmented the resolving power further, but are precluded by electrical breakdown in the gap. Replacing He by hydrogen with much higher breakdown threshold allows [8] reducing the $\mathrm{N}_{2}$ fraction at $E_{\mathrm{D}}=27 \mathrm{kV} / \mathrm{cm}$ to $\sim 10 \%$, and $R$ for $1+$ ions reaches up to $\sim 180$.

Another path involves doping the gas with vapors such as water or alcohols that reversibly complex to ions, solvating them at lower ion temperatures during the weak-field segment and desolvating at higher temperatures in the strong-field segment [17-19]. This process disproportionately elevates the ion-molecule cross sections at low $E$, which expands the difference between mobilities at high and low $E$ when the first exceeds the second. This strategy has been effective for smaller singly-charged ions typical of metabolites or signatures of explosives, but not so far for multiply-charged peptides or proteins.

As an instrumental method is perfected, the resolution and precision often become limited by parameter fluctuations more than fundamental constraints. To illustrate, early linear time-offlight MS provided $R \sim 100$, determined largely by the initial spread of ion velocities and Coulomb repulsion, with the stability of voltage drop besides the point [21]. That spread has been effectively addressed in orthogonal-acceleration reflectron TOF MS systems, where $R \sim 10^{3}-10^{4}$ is affected by factors such as spatial nonuniformity of electric field, jitter in detector circuits, and (most relevant to this work) power supply instability [22, 23]. Likewise in FAIMS, raising $R$ from $\sim 10$ to $>10^{2}$ has brought the stability of experimental parameters to the forefront. A major one is the voltage across the gap, incorporating the asymmetric waveform and "compensation voltage" $(\mathrm{CV})$ that produces $E_{\mathrm{C}}$. Here we report a new generator that outputs more stable CVs with finer scan steps. This platform narrows spectral peaks, increasing $R$ by up to $\sim 40 \%$, that is up to $\sim 500$ for multiply-charged peptides.

\section{Instrument Development}

The planar FAIMS device with gap width of $1.88 \mathrm{~mm}$, coupled to an ion trap MS analyzer (LTQ by Thermo Scientific,
Waltham, MA, USA) via electrodynamic funnel interface, has been detailed [8, 13-16]. As described, the sum of CV and bias voltage is added to waveform and applied to one electrode, while a separately generated bias is loaded on the opposite electrode. Both CV and bias are derived from the control PC using a 16-bit digital-to-analog converter (USB-6229 from National Instruments, Austin, TX, USA) with the customary 0$10 \mathrm{~V}$ range and four analog outputs. Previously, that output was amplified to the needed $\sim 130-200 \mathrm{~V}$ range by linear scaling, resulting in the minimum step of $200 \mathrm{~V} / 2^{16}=3.1 \mathrm{mV}$. For software considerations, the actual step was $\sim 7 \mathrm{mV}$. The new design features an adjustable $\mathrm{CV}$ offset and span such that the step is proportional to scanned $\mathrm{CV}$ range. Even for a wide range of $40 \mathrm{~V}$, the step of mere $0.6 \mathrm{mV}$ is negligible compared with the minimum $w \sim 100 \mathrm{mV}$. The variable offset decouples the step from bias and CV and lifts the limitations on bias and $\mathrm{CV}$ ranges, which allows setting higher absolute $\mathrm{CV}$ s while keeping the maximum resolving power and optimum bias for best ion transmission.

More importantly, the original amplifier utilized the PA85 high voltage op-amps by Cirrus Logic (Austin, TX, USA) with unnecessarily high frequency response and no frequency rolloff filters. These have been replaced by programmable high voltage DC-to-DC converters (C10 from EMCO, Sutter Creek, CA, USA) with $1 \mathrm{kV}$ range, $0.3 \%$ line and load regulation specifications, and $<0.01 \% / \mathrm{h}$ drift of voltage output. These devices used thermally stable passive components for input signal conditioning and a regulated $15 \mathrm{~V}$ power supply. The ripple at full load was $<50 \mathrm{ppm}$ according to specifications and 20-25 ppm on an oscilloscope. The high-frequency noise in the output (200-250 kHz) is suppressed by a two-stage LC filter. This hardware provides a stable and accurate CV scale, in contrast to the (slow) temporal CV drift of up to $\sim 1 \mathrm{~V}$ in the previous system as electronic elements heated during operation. As a bonus, the new amplifier is physically smaller by an order of magnitude. The improved voltage stability with new hardware is evident from Figure 1 and Figure S1 (Supporting Information), with the peak-to-peak $\mathrm{CV}$ excursions measured over the 2-60 s periods dropping from $\sim 35-40 \mathrm{mV}$ to $\sim 8-9 \mathrm{mV}$.

Operational parameters were close to those in earlier studies using $\mathrm{He} / \mathrm{N}_{2}$ and $\mathrm{H}_{2} / \mathrm{N}_{2}$ gases with the waveform amplitude (dispersion voltage, DV) of $5.4 \mathrm{kV}$. The gas flow to FAIMS unit $(Q)$ was "normal" $(2 \mathrm{~L} / \mathrm{min})$ or "reduced" $(0.57-0.76 \mathrm{~L} / \mathrm{min})$, translating into the filtering time $(t)$ of "standard" $0.2 \mathrm{~s}$ or "extended" $0.5-0.7 \mathrm{~s}$, respectively [16]. Solutions in 50/49/1 methanol/water/acetic acid $(\sim 10 \mu \mathrm{M})$ were infused to the ESI source at $0.4-1 \mu \mathrm{L} / \mathrm{min}$. The scan speeds were $1-2 \mathrm{~V} /(\mathrm{cm} \times \mathrm{min})$. The $\mathrm{He}$ fractions in $\mathrm{He} / \mathrm{N}_{2}$ here were $46.5 \%-48 \%$ (i.e., below the previous maximum of $50 \%)[15,16]$ to provide a wider margin of safety against electrical breakdown. Also, the gas pressure in the FAIMS gap was somewhat higher than in the previous experiments because of weather conditions. The mean peak widths $(<w>)$ and $R$ values were derived from replicate analyses, with error margins stated as $95 \%$ confidence intervals. 


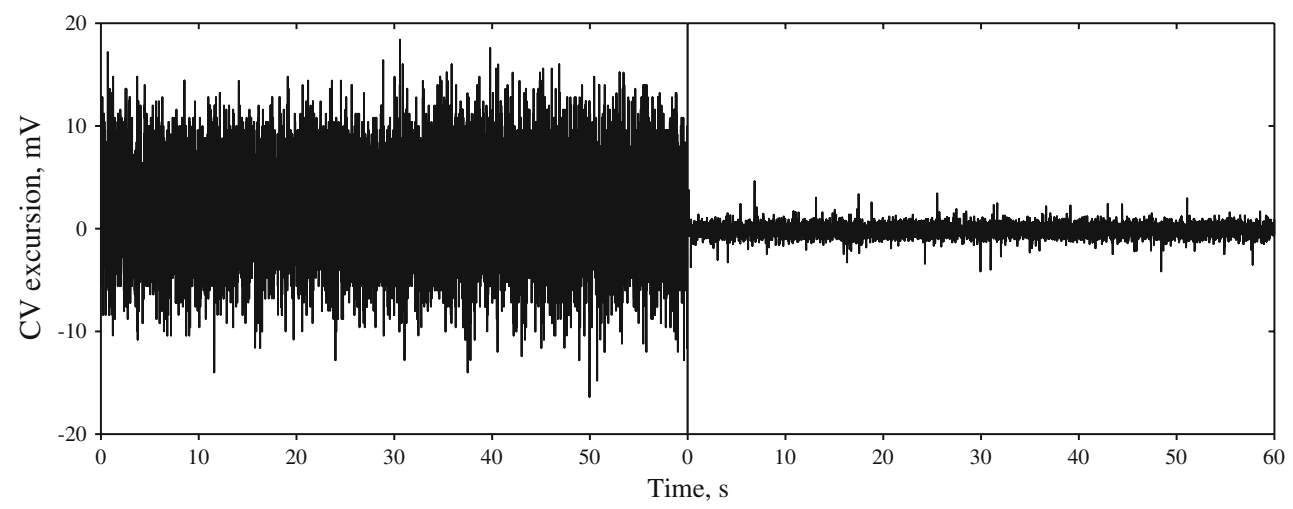

Figure 1. Oscilloscope traces for CV output from the generator over $60 \mathrm{~s}$ with the previous (left panel) and present (right panel) systems. A version including the data with finer time resolution is shown in Figure $\mathrm{S} 1$

\section{Results}

Evaluation started from the common standard of reserpine (1+) that produced a single FAIMS peak [14-16]. That was now found at $E_{\mathrm{C}}=53.9 \mathrm{~V} / \mathrm{cm}$, less than the previous $[15,16] E_{\mathrm{C}}=$ $62.7 \mathrm{~V} / \mathrm{cm}$ because of lower He concentration ( $46.5 \%$ versus $50 \%$ ), slightly higher gas pressure, and more accurate $E_{\mathrm{C}}$ scale as explained above. With $t=0.7 \mathrm{~s}$, the three runs comprising 43 replicates (Figure S2, Supporting Information) had similar $\langle w\rangle$ and error margins, with overall $\langle w\rangle=0.785 \pm 0.020 \mathrm{~V} / \mathrm{cm}$ and thus $R=69 \pm 2$. This is $15 \%$ better than the previous [16] $R=60$ despite lower $E_{\mathrm{C}}$, the gain at same $E_{\mathrm{C}}$ is $33 \%$.

As the discreteness, jitter, and drift of $\mathrm{CV}$ in preceding electronics were in absolute terms and thus broadened all peaks by similar margins, the relative advantage of new system must maximize for the narrowest features. Hence, performance was tested for our benchmark peptide Syntide 2 (S2) 3+ that gave rise to sharp FAIMS peaks $[8,14-16]$. At $50 \% \mathrm{He}$ and extended $t$, the spectrum consisted of a smaller feature I and dominant peak II at higher $E_{\mathrm{C}}=242 \mathrm{~V} / \mathrm{cm}$ (with $\langle w\rangle=0.742 \pm 0.052 \mathrm{~V} / \mathrm{cm}$ and $R=$ $328 \pm 23$, the highest achieved in FAIMS [16]). That spectrum was reproduced here (Figure 2a, b), with lower $E_{\mathrm{C}}$ values $(223 \mathrm{~V} /$ $\mathrm{cm}$ for II) because of smaller He fraction (48 \%) and, again, higher ambient pressure and more accurate $E_{\mathrm{C}}$ scale. The relative $E_{\mathrm{C}}$ shifts compared with previous data at the same gas composition depend on the species because (1) different ions have unequal $K(E)$ and, thus, $E_{\mathrm{C}}\left(E_{\mathrm{D}}\right)$ dependences and (2) the $E_{\mathrm{C}}$ scale offset translates into different relative changes for different $E_{\mathrm{C}}$ ranges. A window around II was scanned in four runs with 66 total spectra (Figure 2c, Figure S3 in Supporting Information). The mean $w$ and error margins for these runs were also close, with overall $\langle w\rangle=0.538 \pm 0.019 \mathrm{~V} / \mathrm{cm}$ and thus $R=415 \pm 15$. This is a $38 \%$ resolution gain over [16] at same $E_{\mathrm{C}}$ and $27 \%$ gain over the maximum $R=328 \pm 23$ therein, despite lower $E_{\mathrm{C}}$.

Replacing $\mathrm{He} / \mathrm{N}_{2}$ by $\mathrm{H}_{2} / \mathrm{N}_{2}$ with equal $\mathrm{N}_{2}$ fraction changes FAIMS spectra little [8], except peaks narrow slightly because of greater ion mobility in $\mathrm{H}_{2}$. Hence, the benefit of new driver for mixtures containing $\mathrm{He}$ and $\mathrm{H}_{2}$ should be similar. Indeed, at $50 \% \mathrm{H}_{2}$ and extended $t$, the same peak II has $E_{\mathrm{C}}=228.4 \mathrm{~V} / \mathrm{cm}$ and, based on 37 replicates, $\langle w>=0.519 \pm 0.027 \mathrm{~V} / \mathrm{cm}$ and $R=441 \pm 23$ (Figure S4, Supporting Information).

Higher hydrogen content permits similar or higher resolution at shorter filtering times [8]. Previous analyses of S2 with $z=3$ and 4 were limited [8] to $\mathrm{H}_{2}$ fractions under $60 \%-70 \%$ by insufficient $\mathrm{CV}$ range and severe peak shape distortions due to $\mathrm{CV}$ jitter. We now extended the measurements to the maximum $\mathrm{H}_{2}$ fraction that avoids breakdown, and $E_{\mathrm{C}}$ values continue increasing (Figure 3). The slope of $E_{\mathrm{C}}$ as a function of $\mathrm{H}_{2}$ content is first rising and then dropping above $\sim 75 \% \mathrm{H}_{2}$, perhaps reflecting the non-Blanc enhancement of $E_{\mathrm{C}}$ and resolving power in mixtures of gases with disparate molecular masses [24]. This effect has been observed for "type A" ions with positive $K(E)$ slope and, thus, negative $E_{\mathrm{C}}\left(\right.$ at $E_{\mathrm{D}}>0$ ) in $\mathrm{N}_{2} / \mathrm{CO}_{2}$ mixtures [24, 25], but not "type $C$ " ions with negative $K(E)$ slope and thus $E_{\mathrm{C}}>0$ (perhaps because the He fraction in
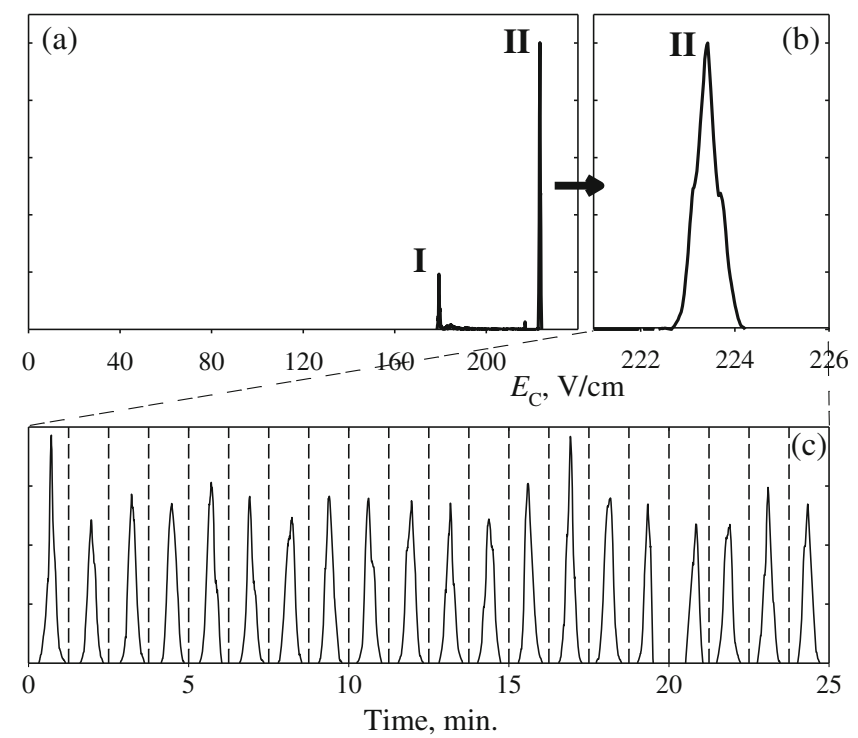

Figure 2. Measurements for Syntide 2 (3+ ion): (a) full spectrum, (b) a window around the peak II, (c) a run of 20 consecutive replicate windows, each scanned in $75 \mathrm{~s}$. Four runs with 66 windows total are shown in Figure S2. Temporal variation of the signal seen here is typical for low-intensity ion fluxes from ESI [15] 


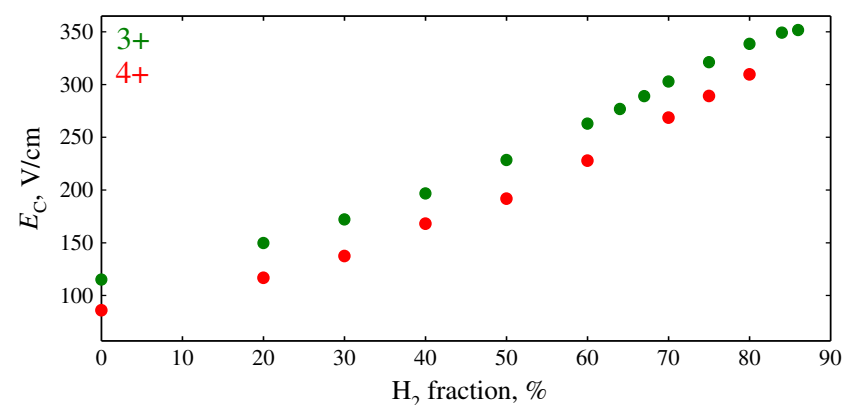

Figure 3. Measured $E_{\mathrm{C}}$ values for Syntide 2 with $z=3$ and 4 in $\mathrm{H}_{2} / \mathrm{N}_{2}$ gas mixtures

$\mathrm{He} / \mathrm{N}_{2}$ mixtures is limited to $\sim 70 \%-75 \%$ by electrical breakdown). At $86 \% \mathrm{H}_{2}$ and $t=0.2 \mathrm{~s}$, the peak II for $3+$ ions comes at $E_{\mathrm{C}}=351.5 \mathrm{~V} / \mathrm{cm}$ and, based on 31 replicates, has $\langle w\rangle=0.764 \pm 0.047 \mathrm{~V} / \mathrm{cm}$ and $R=462 \pm 29$ (Figure S5, Supporting Information). This value exceeds $R \sim 220$ achieved [15] for same peak in equal time using $\mathrm{He} / \mathrm{N}_{2}$ by over 2 -fold and the highest FAIMS resolving power previously demonstrated under any circumstances [16] by $40 \%$.

When measuring physical quantities such as bond energies, one usually accepts the average of consecutively acquired data. However, such averaging arguably underestimates the metrics (e.g., resolution or sensitivity) of analytical methods, where using the superior of several replicates is routine. The expectation value for best of $n$ replicates is the mean of upper $1 / n$ part of statistical sample ranked by the metrics in question. With a reasonable $n$ of 2 or 3, the calculated $R$ values (Table 1 ) exceed the averages of all replicates by $7 \%-10 \%$ (for reserpine) and $13 \%-20 \%$ (for S2), indicating that even better resolution is possible. Such deviations are caused by significant variations of peak widths and associated scatter of $E_{\mathrm{C}}$ values obvious in the spectra, especially for S2 ions where the resolving power is much higher. These variations must ensue from fluctuations of instrumental parameters besides $\mathrm{CV}$ while scanning across a peak. Stabilizing those parameters (mainly DV and gas pressure) along with the CV dealt with here should advance FAIMS performance further. As $E_{\mathrm{C}}$ values in most cases are controlled by $E_{\mathrm{D}} / N$ (where $N$ is the gas number density) and not $E_{\mathrm{D}}$ per se [1,2], stabilizing that ratio by measuring $N$ in real time and scaling DV in proportion as in the SelexIon system (AB SCIEX, Framingham, MA, USA)

Table 1. Statistically Expected Resolving Power Metrics for the Best of $n$ tries

\begin{tabular}{lccc}
\hline \multicolumn{1}{c}{ System, data source } & $n=1^{\mathrm{a}}$ & $n=2^{\mathrm{b}}$ & $n=3^{\mathrm{b}}$ \\
\hline Reserpine in $\mathrm{He} / \mathrm{N}_{2}$, Figure S2 & $69 \pm 2$ & $74 \pm 2$ & $76 \pm 3$ \\
Syntide 2 in He/N, Figure S3 & $415 \pm 15$ & $468 \pm 19$ & $494 \pm 24$ \\
Syntide 2 in $\mathrm{H}_{2} / \mathrm{N}_{2}$, Figure S4 & $441 \pm 23$ & $508 \pm 19$ & $528 \pm 22$ \\
Syntide 2 in $\mathrm{H}_{2} / \mathrm{N}_{2}$, Figure S5 & $462 \pm 29$ & $532 \pm 21$ & $549 \pm 27$ \\
\hline
\end{tabular}

${ }^{\mathrm{a}}$ Metrics in the text

${ }^{\mathrm{b}}$ Statistical error margins for $n=2$ and 3 are close to those for $n=1$ despite fewer replicates because the peak widths in the lower half (third) of the distribution are more similar than in the whole

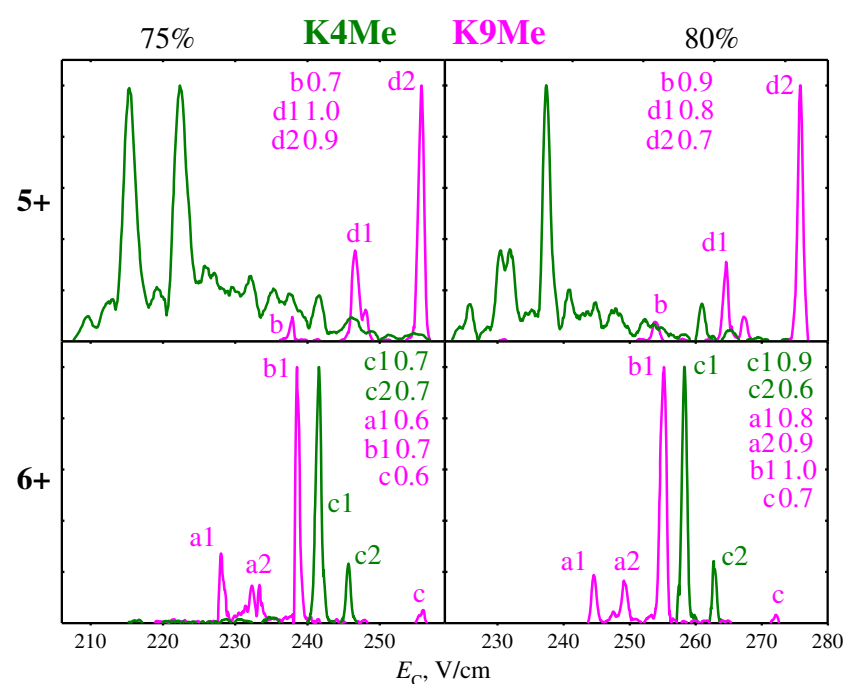

Figure 4. Normalized FAIMS spectra for two monomethylated localization variants of $\mathrm{H} 3$ tail (color-coded) with $z=5$ and 6 , measured using $\mathrm{H}_{2} / \mathrm{N}_{2}$ with $75 \%$ and $80 \% \mathrm{H}_{2}$ (vol/ vol), as labeled. Peaks for different conformers are marked by letters, following reference [16]. The widths $(w, \mathrm{~V} / \mathrm{cm})$ are shown for the well-shaped peaks

[26] should help. However, the behavior of large macro ions appears governed by alignment of their electric dipoles, which depends on $E_{\mathrm{D}}$ and $N$ individually $[27,28]$ rather than $E_{\mathrm{D}} / N$. Then stabilizing $E_{\mathrm{D}} / N$ may be not enough, and both $E_{\mathrm{D}}$ and $N$ may need to be stabilized through operation in a sealed enclosure (e.g., pressurized at 760 Torr) rather than ambient pressure.

Resolution for isomers of macromolecules such as proteins in IMS and FAIMS is often limited not instrumentally, but by the multiplicity of "co-eluting" conformers that materially broaden the peaks [27, 29]. However, large "middle-down" peptides ( $\sim 3 \mathrm{kDa})$ with $z=5-7$ displayed [30, $31]$ the same peak width in FAIMS as smaller tryptic peptides $(\sim 1.5 \mathrm{kDa})$ with $z=3$ or 4 , even at the previously highest $R$ $\sim 300$. Would the separation power gains reported here extend to such analytes? At $70 \% \mathrm{H}_{2}$, the $\mathrm{H} 3$ histone tails

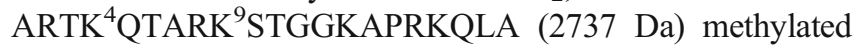

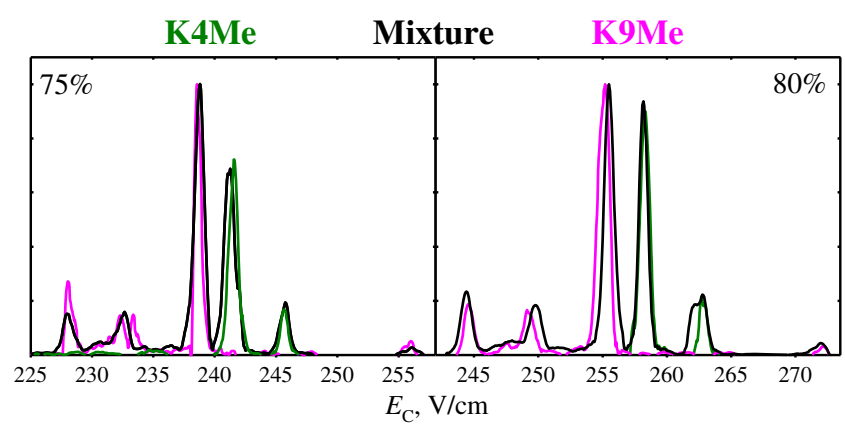

Figure 5. FAIMS spectra for the $\mathrm{K} 4 \mathrm{Me} / \mathrm{K} 9 \mathrm{Me}$ mixture, measured for $6+$ ions using $\mathrm{H}_{2} / \mathrm{N}_{2}$ with $75 \%$ or $80 \% \mathrm{H}_{2}$, as labeled. Vertically scaled spectra for the components are overlaid 
on $\mathrm{K} 4$ or $\mathrm{K} 9$ exhibited [31] peaks with $\langle w\rangle=1.0 \mathrm{~V} / \mathrm{cm}$ (for $z=5$ and 6). Present FAIMS spectra for these regioisomers at $75 \%$ and $80 \% \mathrm{H}_{2}$ (Figure 4) are similar, but the same features narrow to $\langle w\rangle=0.8 \mathrm{~V} / \mathrm{cm}$ while $E_{\mathrm{C}}$ values continue increasing and $R$ goes to $\sim 400$. These separations were confirmed by analyses of 1:1 isomer mixtures (Figure 5). Hence, the resolving power for such larger peptides remains set by instrumental parameters, and the new system improves separation of these species as well. Indeed, defined as the distance between two peaks divided by $\langle w\rangle$, the resolution of major features for $6+$ ions of $\mathrm{K} 4 \mathrm{Me}(\mathrm{b} 1)$ and $\mathrm{K} 9 \mathrm{Me}$ (c1) increases by $\sim 40 \%$ : from 2.5 previously [31] at $70 \% \mathrm{H}_{2}$ to 3.5 here at $80 \% \mathrm{H}_{2}$.

\section{Conclusions}

A new high-definition generator based on DC-to-DC converters provides stable and reproducible FAIMS compensation voltages across a broad range scanned with steps of $<1 \mathrm{mV}$. This narrowed the peaks by $\sim 40 \mathrm{mV}$, while greatly reducing the temporal drift and jitter of their positions. The consequent increase of resolving power $(R)$ and peak resolution varied depending on the peak width, but was $\sim 20 \%-40 \%$ in typical high-resolution analyses using near-maximum $\mathrm{He}$ or $\mathrm{H}_{2}$ fractions where $R \sim 400-500$ can be attained for multiply-charged peptides. This is the highest resolving power demonstrated not only for FAIMS but also for conventional IMS $[9,32,33]$ and compares only with the performance of newly developed cyclotron IMS [9, 33]. The remaining large variation of peak widths and positions because of fluctuations of other instrumental parameters (primarily dispersion voltage and gas pressure) suggests the feasibility of even higher resolution upon their stabilization.

\section{Acknowledgments}

The authors thank Dr. Keqi Tang for discussions and Dr. Yupeng Zheng and Professor Neil Kelleher for sharing the histone samples. This research was supported by NIGMS (8P41 GM 103493-10) and PNNL use-at-facility funds. Work was performed in the Environmental Molecular Sciences Laboratory, a US DoE OBER national scientific user facility at PNNL.

\section{References}

1. Guevremont, R.: High-field asymmetric waveform ion mobility spectrometry: a new tool for mass spectrometry. J. Chromatogr. A 1058, 319 (2004)

2. Shvartsburg, A.A.: Differential Ion Mobility Spectrometry: Nonlinear Ion Transport and Fundamentals of FAIMS. CRC Press, Boca Raton (2008)

3. Shvartsburg, A.A., Smith, R.D.: Optimum waveforms for differential ion mobility spectrometry (FAIMS). J. Am. Soc. Mass Spectrom. 19, 1286-1291 (2008)

4. Schneider, B.B., Covey, T.R., Coy, S.L., Krylov, E.V., Nazarov, E.G.: Planar differential mobility spectrometer as a pre-filter for atmospheric pressure ionization mass spectrometry. Int. J. Mass Spectrom. 298, 4554 (2010)
5. Buryakov, I.A., Krylov, E.V., Makas, A.L., Nazarov, E.G., Pervukhin, V.V., Rasulev, U.K.: Separation of ions according to mobility in a strong electric field. Sov. Tech. Phys. Lett. 17, 446-447 (1991)

6. Purves, R.W., Guevremont, R.: Electrospray ionization high-field asymmetric waveform ion mobility spectrometry-mass spectrometry. Anal. Chem. 71, 2346-2357 (1999)

7. Guevremont, R., Barnett, D.A., Purves, R.W., Vandermey, J.: Ultrahigh-throughput proteomics using fast RPLC separations with ESI-MS/ MS. Anal. Chem. 72, 4577-4584 (2000)

8. Shvartsburg, A.A., Smith, R.D.: Accelerated high-resolution differential ion mobility separations using hydrogen. Anal. Chem. 83, 9159-9166 (2011)

9. Shen, Y., Zhang, R., Moore, R.J., Kim, J., Metz, T.O., Hixson, K.K., Zhao, R., Livesay, E.A., Udseth, H.R., Smith, R.D.: Automated 20 Kpsi RPLC-MS and MS/MS with chromatographic peak capacities of 10001500 for and capabilities for proteomics and metabolomics. Anal. Chem. 77, 3090-3100 (2005)

10. Merenbloom, S.I., Glaskin, R.S., Henson, Z.B., Clemmer, D.E.: Highresolution ion cyclotron mobility spectrometry. Anal. Chem. 81, 14821487 (2009)

11. Barnett, D.A., Ells, B., Guevremont, R., Purves, R.: Application of ESIFAIMS-MS to the analysis of tryptic peptides. J. Am. Soc. Mass Spectrom. 13, 1282-1291 (2002)

12. Shvartsburg, A.A., Tang, K., Smith, R.D.: Differential ion mobility separations of peptides with resolving power exceeding 50. Anal. Chem 82, 32-35 (2010)

13. Shvartsburg, A.A., Li, F., Tang, K., Smith, R.D.: High-resolution field asymmetric waveform ion mobility spectrometry using new planar geometry analyzers. Anal. Chem. 78, 3706-3714 (2006)

14. Shvartsburg, A.A., Danielson, W.F., Smith, R.D.: High-resolution differential ion mobility separations using helium-rich gases. Anal. Chem. 82, 2456-2462 (2010)

15. Shvartsburg, A.A., Prior, D.C., Tang, K., Smith, R.D.: High-resolution differential ion mobility separations using planar analyzers at elevated dispersion fields. Anal. Chem. 82, 7649-7655 (2010)

16. Shvartsburg, A.A., Smith, R.D.: Ultrahigh-resolution differential ion mobility spectrometry using extended separation times. Anal. Chem. 83, 23-29 (2011)

17. Schneider, B.B., Covey, T.R., Coy, S.L., Krylov, E.V., Nazarov, E.G.: Chemical effects in the separation process of a differential mobility/ mass spectrometer system. Anal. Chem. 82, 1867-1880 (2010)

18. Blagojevic, V., Chramow, A., Schneider, B.B., Covey, T.R., Bohme, D.K.: Differential mobility spectrometry of isomeric protonated dipeptides: modifier and field effects on ion mobility and stability. Anal. Chem. 83, 3470-3476 (2011)

19. Rorrer, L.C., Yost, R.A.: Solvent vapor effects on planar high-field asymmetric waveform ion mobility spectrometry. Int. J. Mass Spectrom. 300, 173-181 (2011)

20. Shvartsburg, A.A., Tang, K., Smith, R.D.: Optimization of the design and operation of FAIMS analyzers. J. Am. Soc. Mass Spectrom. 16, 2 $12(2005)$

21. Wiley, W.C., McLaren, I.H.: Time-of-flight mass spectrometer with improved resolution. Rev. Sci. Instrum. 26, 1150-1157 (1955)

22. Guilhaus, M.: Principles and instrumentation in time-of-flight mass spectrometry. J. Mass Spectrom. 30, 1519-1532 (1995)

23. Dodonov, A.F., Kozlovski, V.I., Soulimenkov, I.V., Raznikov, V.V., Loboda, A.V., Zhou, Z., Horwath, T., Wollnik, H.: High-resolution electrospray ionization orthogonal injection time-of-flight mass spectrometer. Eur. J. Mass Spectrom. 6, 481-490 (2000)

24. Shvartsburg, A.A., Tang, K., Smith, R.D.: Understanding and designing field asymmetricwaveform ion mobility spectrometry separations in gas mixtures. Anal. Chem. 76, 7366-7374 (2004)

25. Barnett, D.A., Purves, R.W., Ells, B., Guevremont, R.: Separation of o-, $\mathrm{m}-$, and p-phthalic acids by high-field asymmetric waveform ion mobility spectrometry (FAIMS) using mixed carrier gases. J. Mass Spectrom. 35, 976-980 (2000)

26. Schneider, B.B., Covey, T.R., Coy, S.L., Krylov, E.V., Nazarov, E.G.: Control of chemical effects in the separation process of a differential mobility mass spectrometer system. Eur. J. Mass Spectrom. 16, 57-71 (2010)

27. Shvartsburg, A.A., Noskov, S.Y., Purves, R., Smith, R.D.: Pendular proteins in gases and new avenues for characterization of macromolecules by ion mobility spectrometry. Proc. Nat. Acad. Sci. U.S.A. 106, 6495-6500 (2009) 
28. Shvartsburg, A.A., Smith, R.D.: Protein analyses using differential ion mobility microchips with mass spectrometry. Anal. Chem. 84, 72977300 (2012)

29. Shelimov, K.B., Clemmer, D.E., Hudgins, R.R., Jarrold, M.F.: Protein structure in vacuo: the gas phase conformations of BPTI and Cytochrome c. J. Am. Chem. Soc. 119, 2240-2248 (1997)

30. Shvartsburg, A.A., Zheng, Y., Smith, R.D., Kelleher, N.L.: Ion mobility separations of variant histone tails extending to the middle-down range. Anal. Chem. 84, 4271-4276 (2012)
31. Shvartsburg, A.A., Zheng, Y., Smith, R.D., Kelleher, N.L.: Separation of variant methylated histone tails by differential ion mobility. Anal. Chem. 84, 6317-6320 (2012)

32. Srebalus, C.A., Li, J., Marshall, W.S., Clemmer, D.E.: Gas-phase separations of electrosprayed peptide libraries. Anal. Chem. 71, 39183927 (1999)

33. Glaskin, R.S., Valentine, S.J., Clemmer, D.E.: A scanning frequency mode for ion cyclotron mobility spectrometry. Anal. Chem. 82, 8266$8271(2010)$ 